\title{
10
}

\section{The Thin Line Between Civility and Incivility: Fostering Reflection and Self-Awareness to Create a Civil Learning Community}

\author{
Zopito Marini \\ Brock University
}

Incivility is a critical, but under-examined aspect of teaching and learning. It has important implications for the academic success of students and the university as a whole. Bullying research offers a unique lens through which this type of anti-social behaviour can be understood with a view of developing intervention strategies. The exercises outlined in this paper will help professors gain valuable information about their students' understanding of the continuum between civility and incivility. The potential results from this reflective exercise can be an exciting example of the benefits of classroom engagement, where the knowledge gained from participating students is reinvested into their classrooms, thus contributing to their own creation of a civil learning community.

\section{Introduction}

W hile civility is a major characteristic of campus life, given the changing social and cultural role of the university, with its multiple pursuits and the individualist nature of its occupants, civility cannot be assumed or assured. It is apparent that incivility is increasingly becoming an issue of concern for all the major stakeholders, including students, professors, and administrators because the belief that this type of behaviour has both a short and a long-term negative impact on everyone involved (Hirschy \& Braxton, 2004). Civility can be defined as "the ability to act as a 'citizen' of a group and function in a positive manner so that individual engagement can benefit both the individual and the group" (Marini, 2007, pg. 1). According to Boice (1996), the occurrence of classroom improprieties is "more common than uncommon" (pg. 479), hence, there is very little doubt that the teaching capabilities of universities and the learning opportunities of their students are seriously reduced when incivility occurs in classrooms, seminars, and labs.

The purpose of this paper is to share the ex- 
perience of developing a framework aimed at fostering understanding of incivility with a view to creating teaching environments that invite civility, thus nurturing the fragile teaching and learning process. ${ }^{1}$ With this in mind, this paper has three specific aims, namely: 1) to outline a framework to systematically elicit example of behaviours along the incivility and civility continuum; 2) to create a better understanding of the link between incivility and other forms of anti-social behaviours, such as bullying; and 3) to build on these two frameworks to systematically identify incivility and make suggestions for fostering civility.

\section{The Thin Line Between Civility and Incivility}

Although the reasons for the increase in concern with incivility on university campuses may be complex, and not entirely understood, the manifestations and consequences of incivility are concrete and undeniable. For instance, incivility can range from minor annoyances like cell phones ringing during lectures or classes disrupted by loud conversations, to the serious consequences of discussions that turn into insults or the misuse of technology, to the very serious outcomes when threats and intimidation are used and safety becomes an issue. Thus, in terms of understanding its characteristics, it is probably more productive to conceptualize incivility as a continuum that runs from annoying to disruptive to dangerous comportment. Similarly, in terms of consequences, the experiences of incivility can affect a student's academic and personal development, ranging along a severe continuum from short-term disengagement from a course to long-term unfulfilled educational goals (Hirschy \& Braxton, 2004).

One of the major objectives in this type of exercise is to systematically elicit useful information in a group setting with students (or even instructors) to highlight how easy it is to cross the thin line between civility and incivility. In trying to foster specific reflection and self-awareness, I have designed guided group exercises that take participants through a number of focused reflections in a stepwise progression. Figure 1 illustrates the intersection of two continua; the vertical axis represents the continuum from civility to incivility and the horizontal axis represents the continuum of the progression of intentionality.

The development of Figure 1 has seen many versions and has occurred over a number of years, and

\section{$く$ Intentionality $\quad>$}

$\begin{array}{ll}\text { Unintentional } & \text { Intentional } \\ \text { Civility (3) } & \text { Civility (4) }\end{array}$

Civility

乙 $\begin{array}{ll}\text { Unintentional } & \text { Intentional } \\ \text { Incivility (2) } & \text { Incivility (1) }\end{array}$

Figure 1

Unintended and Intended Civility

\footnotetext{
1 This paper is aimed predominantly at helping professors in their efforts to foster civility in their classrooms. However, given the reciprocal and dynamic nature of civility, instructors may find the process of personally engaging and reflecting on these activities beneficial.
} 
it is partly based on concepts related to the field of inviting education and the seminal work of my colleague John Novak of Brock University's Faculty of Education. While working on a monograph with him, I became quite interested in developing a visual representation of John's central idea of providing an inviting educational environment (Di Petta, Novak, \& Marini, 2002). At the time, I was teaching an introductory course in Child and Youth Studies, thus, I attempted to express the ideas on a graph using the vertical axis to indicate the degree of 'inviting' and the horizontal axis to indicate the degree of 'intentionality.' I used the Figure in my class of over 600 students to focus discussion on each of the quadrants. More recently, when looking for a depiction that would allow me to foster reflection on the thin line between civility and incivility, I returned to this design where I kept the intentionality on the same axis and used the vertical axis to represent the continuum between civility and incivility.

\section{Fostering reflection on the two continua involving civility and intentionality}

Depending on the course (or the purpose of a particular presentation), the content of Figure 1 can be engaged in a number of ways. Obviously, it would be quite appropriate to divide the audience into four groups and assign a roughly similar number of participants to each quadrant, allow them time to generate and discuss concrete examples that reflect the focus of the assigned quadrant, and ask each group to report to the entire audience. One of the effects of calling on groups to report in chronological order, from 1 to 4 , is that the audience engages in a journey, beginning with the worst possible type of behaviour, characterized by deliberate and intentional incivility (which is the most undesirable), and ending with the behaviour represented in quadrant 4 , characterized by intentional civility (which is the most desirable). Thus, responses from quadrant 1 may be characterized by cruel and demeaning comments aimed at hurting someone's feelings, such as: "What is wrong with you? You can not be that dumb!" Responses from quadrant 2 may spring more from thoughtlessness than an aim to hurt. Thus, items in this quad- rant could involve making fun of someone's situation without knowing the person's circumstances, such as exemplified in a statement: "You know, only those kinds of people wear those close." Responses from quadrant 3 are characterized by a manifestation of civility where the person performing the act may do so routinely, and not be aware of its impact, such as: "Opening doors on the way into a lecture." Finally, responses from quadrant 4 are characterized by purposefully matching the right behaviour to the right situation. In other words, the person knows why a civility act is necessary as well as its possible impact, such as "Helping an older student pick up books they just dropped, even if you are going to be late for class." While some students may find differentiating between the quadrants challenging, it is worth reiterating for them that quadrants 2 and 3 are populated by acts high in intentionality, behaviours in quadrants 2 and 3 are more accidental in naute.

The result of engaging the audience through Figure 1 provides a rich and varied list of acts of civility and incivility, which can then become material to be identified and built upon to eventually provide suggestions for intervention. However, as part of the process it is important to also reflect on the difficulties encountered in generating examples in each quadrant and just as important appreciate how "thin" the line is between the quadrants. To help categorize and make sense of the responses generated using Figure 1 , the facilitator may use the framework outlined in the next section.

\section{Understanding of the Links Between Incivility and Bullying}

One way to understand the slippery slope of incivility and other anti-social behaviours, such as bullying, is to outline some of the major findings of the bullying literature and highlight the potential links between incivility and bullying. An example of a possible conceptual bridge between incivility and our research on bullying is in the definition we use, which highlights the repeated and systematic use and abuse of power involved in bullying to obtain instrumental and social goals (Marini, Dane, Bosacki, \& YLC-CURA, 
2006; Marini \& Dane, 2008).

In a previous work (Marini, 2007), I argued that it seems plausible to suggest that the area of study related to civility could benefit from research contributions grounded in related cognate fields of study particularly those pertaining to the general area of interpersonal conflicts, antisocial behaviour and aggression, such as the systemic aggression manifested in bullying. Thus, it seems that the bullying literature can be quite informative on this aspect of incivility by placing it in the larger continuum related to anti-social acts. A critical concept to keep in mind is the idea that many acts of incivility are subtle and easily dismissed as not a 'big deal.' However, extensive bullying research makes clear that, if allowed to persist, incivility can slowly undermine the necessary social fabric needed for group func- tioning (Lim, Cortina, \& Magley, 2008).

Aspects of bullying that can contribute to the understanding of incivility

Bullying is a sub-type of aggression aimed primarily at harming the relationship between peers (Marini et al., 2006; Pepler, Jiang, Craig, \& Connolly, 2008) and, while a comprehensive examination of the vast bullying literature is outside the scope of the present paper, a number of central issues will be used to inform our understanding of incivility, including: 1) the predominant focus on the physical aspects of bullying; 2) the lack of understanding of the heterogenous nature of bullying; 3) the serious underestimation of the pervasiveness and impact of indirect types of bullying; 4) the short and long-term consequences
A) Forms of Attack

Direct

Indirect

B) Function of Attack

Reactive

Proactive

C) Types of Involvement

Single role

Dual Role $\rightarrow$

\section{$\rightarrow$}

$\rightarrow$

\section{How is bullying carried out? or, what does it look like?}

Manifestations of Bullying
Covert attacks, harming others by manipulating peer relationships

\begin{abstract}
or, what does it look like?
\end{abstract}
Overt confrontations, involving physical \& verbal attacks

Goals of Bullying

Why is bullying carried out? or, what is the motivation?

Defensive attacks, frustration driven, hostile expressions (i.e., reaction to perceived provocations)

Predatory attacks, unprovoked, goal-directed (use of aversive acts to obtain instrumental and social goals)

Roles Played in the Bullying

What role does the individual have in bullying?

Bully, Victim and Bystanders

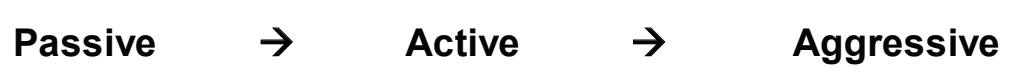

Marini et al, (2006; in press)

Figure 2

Multidimensional Bullying Identification Model 
of this type of meanness; and 5) most importantly, the failure to appreciate the transformation of bullying to fit in different settings such as the world of academia. A particularly valuable distinction borrowed from the bullying literature (Marini et al., 2006; Marini, Dane, \& Kennedy, in press), which focuses on the forms, functions and types of involvement, is illustrated in Figure 2.

\section{Forms of bullying}

A persistent notion has been that typical bullying behaviours involve predominantly physical and other overt acts, such as verbal aggression. Nothing could be further from the truth. In fact, once the myth of the exclusive use of physical aggression was put to rest, researchers began to take a serious look at other forms of bullying (Leenaars, Dane, \& Marini, 2008; Vaillancourt, 2005). As a result, and to the surprise of many people, a number of other types of bullying have been identified. One of the common characteristics of non-physical types of bullying is the fact that they are committed, largely, in a covert manner. Thus, this type of bullying can be classified under the umbrella of "indirect" bullying, which encompasses a large number and types of harmful behaviours that may include social, relational and, most recently, cyber bullying, usually carried out in the absence of the victim, and in many cases, out of the view of others. Indirect bullying tends to afford the victimizer some anonymity and increase the likelihood of escaping detection. The current thinking on the best way to capture the forms of bullying makes use of a juxtaposition of direct and indirect bullying.

\section{Function of bullying}

The second dimension of bullying is the function it serves for the perpetrator. Central to this aspect is the concern related to the understanding of the motivation for students to engage in bullying. In other words, why do students bully others? Finding an answer to this question is of fundamental importance, for it can have an impact on the type of intervention we may put in place. While the motives may be many and complex, usually they can be parsed out into two major categories; namely, reactive and proactive. As shown in Figure 2, students are likely to become bullies because they react to a "perceived" hostile act directed towards them, even if the originator of the act does not mean to cause harm. An example of reactive bullying is likely to take place in the middle of a class discussion on a potentially volatile topic such as poverty, euthanasia, or racism. In the heat of a spirited discussion, words may be said in an unreflective manner, causing a sensitive person to overreact and retaliate. In contrast, proactive bullying is planned and calculated, does not involve hostility, and is usually directed to acquire rewards in the form of goods or social status.

\section{Types of involvement}

The involvement can range from single to multiple, and from passive, to active, to aggressive. For instance, there may be students who are purely victims or bullies, while others are both. Similarly, to revisit the continuum of incivility mentioned above, a distinction can be made between those students who are passively uncivil, for example reading the newspaper in class, to those who are involved more actively, such as those who talk during lectures, and finally to those students who are uncivil in an aggressive manner, such as those who publicly and loudly question the fairness of a grade received in an assignment.

\section{Design for a Civil Learning Community}

Engaging Figure 2 facilitates the building of conceptual bridges between incivility and bullying that can extend beyond the anti-social similarities of the two concepts and to sustentative comparisons related to the "form" (e.g., type) and "function" (e.g., motivation) of the two behaviours. For example, our understanding of incivility could be considerably enhanced by making a sharper distinction between various types of incivility, and between acts of incivility committed overtly and those carried out covertly. Furthermore, it would be informative to differentiate between uncivil behaviours that arise because of reactions to a "perceived" provocation, those that arise 
unintentionally, and those that are planned and intentional.

\section{Preparing for intervention}

To the extent that it is possible, it would be beneficial to pull together the responses generated from engaging Figure 1 and to invest some time to categorize them using the template in Figure 2. In other words, it would be constructive to see how each of the following categories are represented, including: 1) forms (direct vs. indirect); 2) function (reactive vs. proactive); 3) types of involvement (single vs. dual, and passive, active vs. aggressive); and 4) severity: low (annoying), mid (disruptive), and high (dangerous).

Overall, these distinctions are noteworthy for they may help to point the way towards general intervention strategies. For instance, while direct and reactive incivilities can be usually addressed by instructional and behavioural interventions, which may include explicit statements addressing the issue, other acts of incivility, such as those carried out indirectly and are planned (e.g., covertly provoking a sensitive student), need to be addressed by different means that include the fostering of good learning relationships between students and between students and their instructors (Marini \& Dane, 2008; Marini et al., in press).

In addition to the general intervention just mentioned, in terms of more specific and targeted strategies, it is beneficial to distinguish between disruptive classroom behaviours that spring from a lack of knowledge of the rules and norms expected in a lecture (e.g., students do not know any better) from acts of incivility that arise because of a lack of selfcontrol, where students may react to perceived provocation (e.g., the classical overreaction to a comment one does not agree with). In case of the former, a well-structured syllabus clearly outlining the expectations of the course will go a long way in preventing much of this type of incivility. In the latter case, engaging students in a discussion of civility culminating in a 'shared statement of civility' may go a long way in establishing and nurturing relationships with other members of a civil learning community, making sure that a class, seminar or lab runs smoothly, even under difficult circumstances.

\section{References}

Boice, R. (1996). Classroom incivilities. Research in Higher Education, 37, 453-485.

Di Petta, T., Novak, J.M., \& Marini, Z.A. (2002). Inviting on-line education. Bloomington, IN: Educational Foundation.

Hirschy, A.S. \& Braxton, J.M. (2004). Effects of student classroom incivilities on students. New Directions in Teaching and Learning, 99, 67-76.

Leenaars, L., Dane, A., \& Marini, Z.A. (2008). Evolutionary perspective on indirect victimization in adolescence: The role of attractiveness, dating and sexual behavior. Aggressive Behavior, 34, 404-415.

Lim, S., Cortina, L.M., \& Magley, V.J. (2008). Personal and workgroup incivility: Impact on work and health outcomes. Journal of Applied Psychology, 93, 95-107.

Marini, Z.A. (2007). Understanding and fostering civility in university classrooms: Seminar leaders as agents of civic engagement. Research proposal: Brock Chancellor's Chairs for Teaching Excellence. Unpublished manuscript, Brock University.

Marini, Z.A., \& Dane, A.V. (2008). Matching interventions to bullying subtypes: Ensuring programs fit the multifaceted needs of children involved in bullying. In D. Pepler \& W. Craig (Eds.), An international perspective on understanding and addressing bullying (pp. 97-126). Bloomington, IN: AuthorHouse.

Marini, Z.A, Dane, A., Bosacki, S., \& YLCCURA. (2006). Direct and indirect bullyvictims: Differential psychosocial risk factors associated with adolescents involved in bullying and victimization. Aggressive Behavior, 32, 551-569. 
Marini, Z. A., Dane, A., \& Kennedy, R. (in press). Multiple pathways to bullying: Educational implications of individual differences in temperament and brain function. In $\mathrm{M}$. Ferrari \& L. Vuletic (Eds.), The developmental relations between mind, brain, and education: Essays in honor of Robbie Case. New York: Springer.

Pepler, D., Jiang, D., Craig, W., \& Connolly, J. (2008). Developing trajectories of bullying and associated factors. Child Development, 79, 325-338.

Vaillancourt, T. (2005). Indirect aggression among humans: Social construct or evolutionary adaptation? In R.E. Tremblay, W.H. Hartup, \& J. Archer (Eds.), Developmental origins of aggression (pp. 158-177). NY: Guilford Press.

\section{Biography}

Zopito Marini is a developmental and educational psychologist, and a Professor of Child and Youth Studies at Brock University in St. Catharine's, Ontario. His dedication to his students and his commitment to the development of innovative pedagogy has received many awards, including: The Brock University Award for Distinguished Teaching and the OCUFA Teaching Award. 